Mary R. Suchyta

Callie J. Beck

Colin W. Key

Al Jephson

Ramona O. Hopkins

\section{Substance dependence and psychiatric disorders are related to outcomes in a mixed ICU population}

Published online: 16 December 2008

(C) Springer-Verlag 2008

The online version of the original article can be found under doi:10.1007/s00134-008-1263-9.

M. R. Suchyta · A. Jephson · R. O. Hopkins

Department of Medicine, Pulmonary

and Critical Care Division, LDS Hospital,

Salt Lake City, UT, USA

e-mail: mary.suchyta@imail.org

M. R. Suchyta · A. Jephson · R. O. Hopkins ( $)$

Department of Pulmonary and Critical Care Medicine,

Intermountain Medical Center,

5121 South Cotttonwood Street, Murray,

UT 84107, USA

e-mail: mona_hopkins@byu.edu

Tel.: +1-801-5074569

Fax: +1-801-4220602

C. J. Beck · C. W. Key · R. O. Hopkins

Psychology Department, 1001 SWKT,

Brigham Young University,

Provo, UT 84602, USA

R. O. Hopkins

Neuroscience Center, Brigham Young University,

Provo, UT, USA

\section{Erratum to: Intensive Care Med (2008) 34:2264-2267 DOI 10.1007/s00134-008-1263-9}

The legends to Figs. 1 and 2 were unfortunately transposed.

The figures are correct.

The corrected figures are given here.

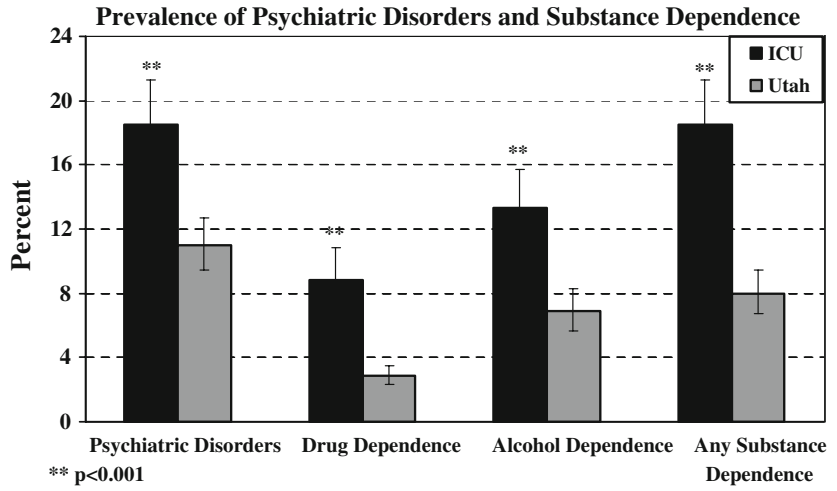

Fig. 1 The prevalence of substance dependence and psychiatric disorders in critically ill patients (black bars) compared to Utah population data (gray bars). Significant differences are denoted with * for $p$ values of $<0.01$ and ** for $p$ values of $<0.001$. Error bars denote the $95 \%$ confidence intervals for the percentages (proportions)

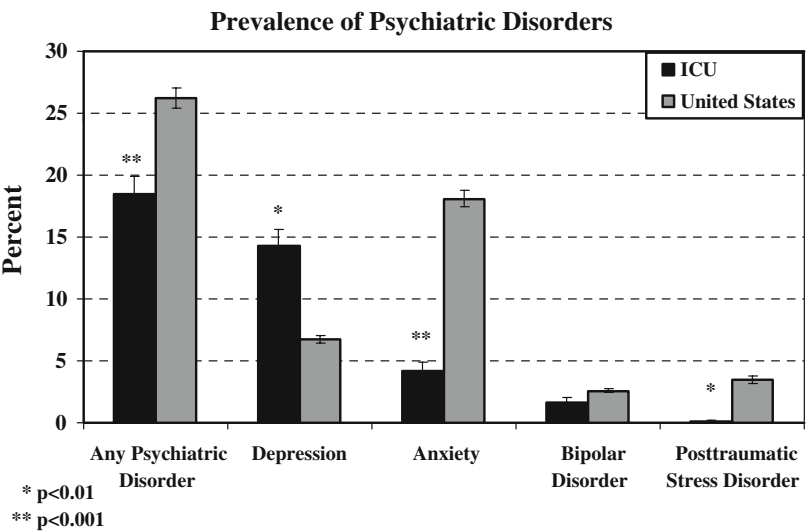

Fig. 2 The prevalence of psychiatric disorders by disorder in critically ill patients (black bars) compared to United States population data (gray bars). Significant differences are denoted with * for $p$ values of $<0.01$ and ** for $p$ values of $<0.001$. Error bars denote the standard error of the percentages (proportions) 